
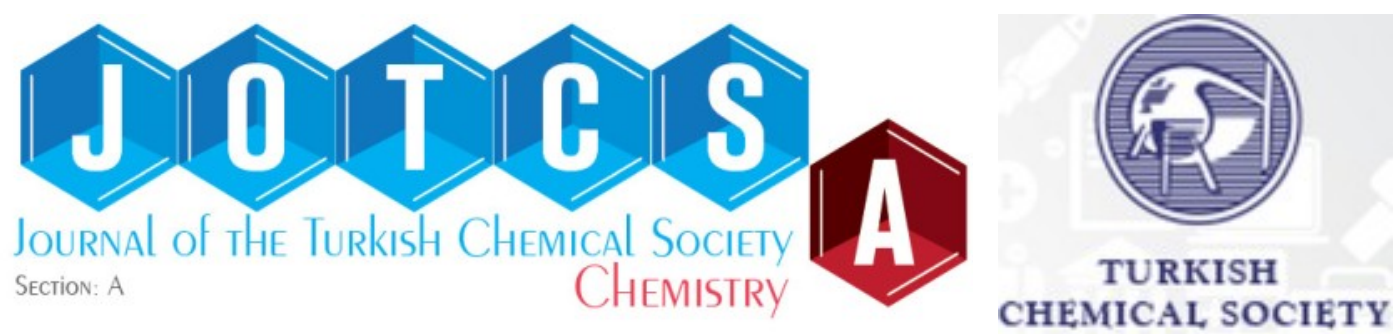

\title{
Determination of the Molecular Mass of Hydrolyzed Fibroin Obtained from Natural Silk Fibroin by Spectrophotometry
}

\author{
Khushnudbek Odilbekovich ESHCHANOV ${ }^{1}$ D , Mukhabbat Matnazarovna BALTAEVA ${ }^{1}$ i \\ ${ }^{1}$ Urgench State University, Department of Chemistry, Urgench, 220100, Uzbekistan
}

\begin{abstract}
In our previous scientific publications, we have recommended spectrophotometry as a method for determining the molecular mass of silk fibroin. As a result of our research, we were able to obtain hydrolyzed fibroin ("HF") with high polyfunctional high sorption properties from natural silk fibroin by thermal methods under acidic conditions and the influence of UHF rays. We used spectrophotometry to determine the molecular mass of "HF" obtained by two different methods. It was observed that there are differences between the molecular masses of "HF" obtained by thermal methods and under the influence of ultra-high frequency (UHF) rays. It was found that the molecular mass of "HF" obtained thermally under acidic conditions was $246,6 \mathrm{kDa}$, and the molecular mass of "HF" obtained under the influence of UHF rays was $307 \mathrm{kDa}$. The main reason for the different molecular masses of "HF" was considered to be the fact that the process duration of "HF" production methods varies.
\end{abstract}

Keywords: Spectrophotometry, hydrolyzed fibroin ("HF"), ultra-high frequency (UHF) rays, UV spectrum, molecular mass.

Submitted: July 10, 2021. Accepted: December 07, 2021.

Cite this: Eschanov KO, Baltaeva M. Determination of the Molecular Mass of Hydrolyzed Fibroin Obtained from Natural Silk Fibroin by Spectrophotometry. JOTCSA. 2022;9(1):115-20.

*DOI: https://doi.org/10.18596/jotcsa.969482.

*Corresponding author. E-mail: olmos77@mail.ru

\section{INTRODUCTION}

Silkworm fiber is a thin, hard, and shiny fiber, a natural textile raw material made from the fluid that comes out of the silkworm's two silk glands. Silk is made up of two strands wrapped around a silkworm cocoon that are not glued together, coated with sericin (silk glue), and glued together. This fiber contains $70-75 \%$ fibroin (protein), $20-$ $25 \%$ sericin, $2-3 \%$ various minerals, $1-1,5 \%$ wax and oils.

Silk is used for silk weaving, baked yarn and in engineering, aviation, aerospace and electrical engineering (1). In production technologies, fibers and films are made on the basis of natural cocoons.
The fibroin in silk is insoluble in water. In hot water, the sericin protein dissolves, which covers the top of the fiber. Silk fiber can withstand temperatures up to $140{ }^{\circ} \mathrm{C}$. When the temperature rises to $140-170{ }^{\circ} \mathrm{C}$, the protein in the fiber undergoes a structural change. The density of the fiber depends on the type of silk. For example, the densities of Mulberry and Tussah silks are 1.33 and $1.32 \mathrm{~g} / \mathrm{cm}^{3}$, respectively. Other types of silk have an average density of $1.6 \mathrm{~g} / \mathrm{cm}^{3}(2,3)$.

Fibroin is a fibrillar protein that forms the polymer basis of natural silk. The primary structure of these proteins depends on the nature of the natural cocoon, the silkworm's diet, time, and other biological factors. The largest mass fraction (90\%) in the fibroin macromolecule corresponds to the amino acid residues Gly, Ala, Tyr, Ser. There is also a very small amount $(\omega<1 \%)$ of Cys in the 
fibroin macromolecule. The polypeptide chain of fibroin contains hydrophilic and hydrophobic amino acid groups in a 6.3:1 ratio. The fibroin molecule consists of crystalline ( $\beta$-structure) and amorphous (a-spiral) parts in which the polymer chain is sequentially arranged $(4,5)$.

Fibroin is insoluble in alcohol, ether, benzene, acetone, carbon disulfide, and other organic solvents. Salts of calcium, strontium, barium, which form a solution in a neutral medium, and hydrogen halide acids, and Schweizer's reagent form colloidal systems in alkaline solutions. Soluble in concentrated phosphate, sulfate, hydrochloric acid, and liquid ammonia at low temperatures (between 9 and $11^{\circ} \mathrm{C}$ ) (6).

Silk fibroin is also soluble in concentrated $\mathrm{ZnCl}_{2}$ solution and ammoniacal solutions of nickel(II) hydroxide. Fibroin is well soluble in copper(II) glycerate and ethylenediamine copper(II) in solutions of dichloroacetic and formic acids. Solutions of $0.7 \%$ to $1 \%$ concentrates of fibroin can be prepared in solution. It is possible to form a fibroin solution in $\mathrm{N}$-methylmorpholine- $\mathrm{N}$-oxide at 74-76 ${ }^{\circ} \mathrm{C}$. Fibroin is well soluble in hydrotron solvents, such as iodides and rhodanides of $\mathrm{Li}^{+}, \mathrm{K}^{+}$, $\mathrm{Na}^{+}$; halides and rhodanides of $\mathrm{Ca}^{2+}, \mathrm{Zn}^{2+}$; di and trichlor (or fluorine) are soluble in acetic acids. With $56 \%$ of NaSCN with $10 \%$ DMSO, the viscosity of silk fibroin at $25{ }^{\circ} \mathrm{C}$ in aqueous solution is well studied, and the following expressions apply to this solution $(6,7)$ :

$$
[\eta]=0.4 \times 10^{-4} M_{w}^{0.58}
$$

Silk fibroin is well soluble in a solvent mixed with $\mathrm{CaCl}_{2}: \mathrm{C}_{2} \mathrm{H}_{5} \mathrm{OH}: \mathrm{H}_{2} \mathrm{O}(8)$. Examination of the solution by UV spectrophotometry revealed that the maximum absorption wavelength is close to 280 $\mathrm{nm}$.

The silk fibroin molecule consists of 3 chains, the heavy chain (which can range from $390 \mathrm{kDa}$ to 500 $\mathrm{kDa})$, the light chain (26 kDa), and the P-25 glycoprotein (25 kDa) (9). The literature indicates that the molecular weight of fibroin is $60-150 \mathrm{kDa}$ (average $84 \mathrm{kDa}$ ) as determined by ultracentrifugation and diffusion methods (10). By measuring the osmotic pressure, it was determined that the molecular mass of silk fibroin is $30 \mathrm{kDa}$ (11).

Silk fibroin was found to be up to $250 \mathrm{kDa}$ in $9.3 \mathrm{M}$ $\mathrm{LiBr}$ solution by SDS-PAGE (8). Silk fibroin was found to be $300 \mathrm{kDa}$ in $\mathrm{CaCl}_{2}$-ethanol solution using the SDS-PAGE method (12).

To determine the molecular mass of silk fibroin, it is necessary to convert it into a solution. We have shown in our previous work that we used spectrophotometry to determine the molecular mass of silk fibroin (13).

As a result of our research, we studied the methods of production of hydrolyzed fibroin with high sorption properties from silk fibroin and determined the optimal conditions. "HF" from silk fibroin fiber was obtained by the thermal method under acidic conditions and the influence of UHF rays $(2450 \mathrm{MHz}$ ). The result is a powdery white "HF". It was studied that the time of obtaining "HF" from silk fibroin under the influence of UHF rays ends 5-6 times faster than the thermal method (14). "HF"s multifunctional high sorbent properties have the potential to be used in pharmaceuticals, cosmetics, food, and other industries.

\section{EXPERIMENTAL SECTION}

\section{Materials}

Fibrous waste of silk (cleaned of additives, Khorezmipagi LLC, Urgench, Uzbekistan), Sodium carbonate (purity 99,9\%), $\mathrm{HCl}$ (chemically pure) was purchased from Chimreaktivinvest (Uzbekistan). Calcium chloride and ethyl alcohol (98\%) were purchased from Fortek company (Uzbekistan).

\section{Instrumentation}

Bidistilled water is obtained from the "GFL 2104 Double distillation water still" device (Germany). The experiments used UV-1800 Shimadzu spectrometer, Thermostat spare parts (Assistant cat. № 3180) (Hamburg, Germany).

\section{Procedure}

Obtaining "HF" thermally in an acidic environment The cocoon is placed in a $500 \mathrm{~mL}$ heat-resistant beaker and a $0.5 \% \mathrm{Na}_{2} \mathrm{CO}_{3}$ solution $(1: 50 \mathrm{\omega} / \mathrm{v})$ is poured over it. Boil a glass of water in a bath for 30 minutes. The fiber is then removed from the beaker and boiled for 10 min with distilled water. The boiled fiber is washed with a mixture of distilled water until salts are removed from the mixture. The fiber is dried in an oven at $70^{\circ} \mathrm{C}$ for 4 hours. Transfer the obtained fiber to a $500 \mathrm{~mL}$ heat-resistant beaker and top with a $3 \% \mathrm{HCl}$ solution $(1: 50 \omega / \mathrm{v})$. Heat in a glass container at a temperature of $90-95{ }^{\circ} \mathrm{C}$ for $80-90 \mathrm{~min}$. The result is a white powdery "HF".

Obtaining "HF" from silk fibroin under the influence of UHF rays

Put cocoon fiber and $0.5 \% \mathrm{Na}_{2} \mathrm{CO}_{3}$ solution (1:50 $\omega / v)$ in a $500 \mathrm{~mL}$ beaker. Boil the solution in a glass for 30 minutes. At the end of the allotted time, remove the fiber from the container and rinse with distilled water (until no $\mathrm{Na}_{2} \mathrm{CO}_{3}$ remains). Transfer the washed fiber to a $500 \mathrm{~mL}$ beaker and top with a $3 \% \mathrm{HCl}(1: 50 \mathrm{\omega} / \mathrm{v})$ solution. 
The glass is placed in the microwave. Hydrolysis of fibroin fibers is carried out under the influence of $510 \mathrm{~W}$ UHF rays $(2450 \mathrm{MHz})$. The result is a white powdery "HF".

Determination of molecular masses of "HF" samples obtained by thermal and UHF rays by spectrophotometry

The measured "HF" powder mass was dissolved in a solution of $\mathrm{CaCl}_{2}: \mathrm{C}_{2} \mathrm{H}_{5} \mathrm{OH}: \mathrm{H}_{2} \mathrm{O}(1: 2: 8 \mathrm{~mol})$ at a temperature of $65^{\circ} \mathrm{C}$. In order to determine the molecular mass of "HF" obtained thermally in an acidic environment, solutions with a concentration of $0.04,0.06,0.0833,0.1,0.125,0.25$, and 0.5 $\mathrm{g} / \mathrm{L}$ were prepared. The UV-1800 Shimadzu spectrophotometer indicated that the maximum absorption wavelength of the prepared solutions of "HF" was $280 \mathrm{~nm}$. The light absorption was determined in a $1 \mathrm{~cm}$ thick $(I)$ cuvette.

The above operations were also performed for "HF" obtained under the influence of UHF rays. To determine the molecular mass of "HF", solutions with concentrations of $0.508,0.14,0.07,0.035$, and $0.0175 \mathrm{~g} / \mathrm{L}$ were prepared. The light absorption of "HF" solutions obtained under the influence of UHF rays was determined.

\section{RESULTS AND DISCUSSION}

The UV spectra of "HF" obtained thermally in an acidic environment were studied (Figure 1 ). The light absorption values of "HF" solutions at $280 \mathrm{~nm}$ were determined and the $\mathrm{A} / \mathrm{I}$ and $\mathrm{C}$ correlation graphs were plotted (Figure 2 ). To determine the molecular mass of "HF", it is necessary to determine the angular length (a) of the graph line $\mathrm{A} / \mathrm{I}-\mathrm{C}$ concerning the $\mathrm{C}$ axis. Molecular mass is determined by the following formula.

$$
M=\frac{\epsilon}{\operatorname{tg} \alpha}
$$

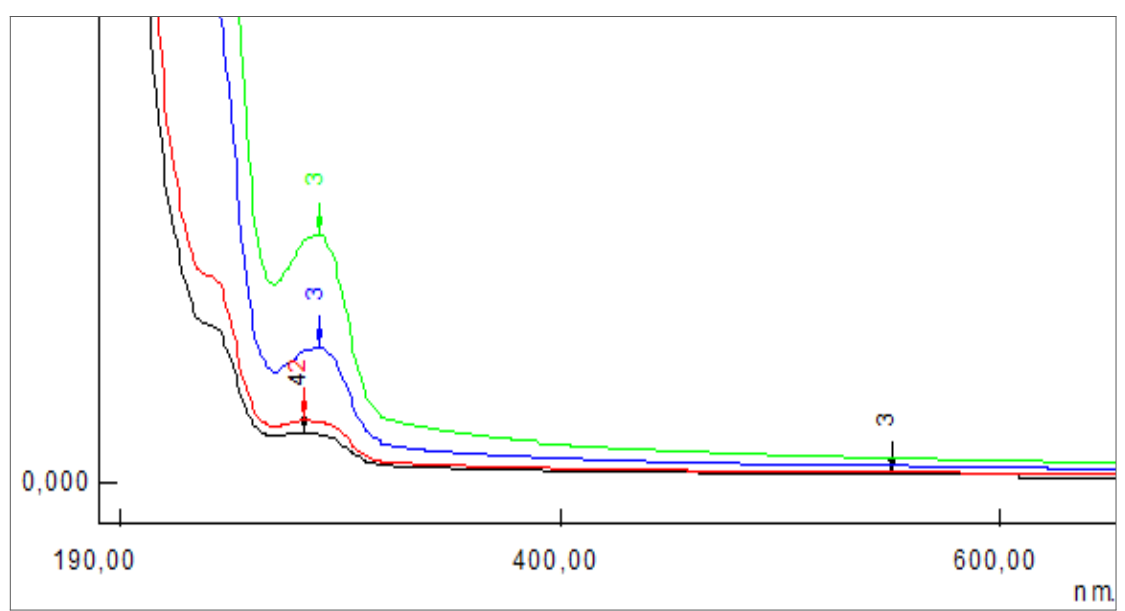

Figure 1: UV spectra of thermally obtained "HF" solutions.

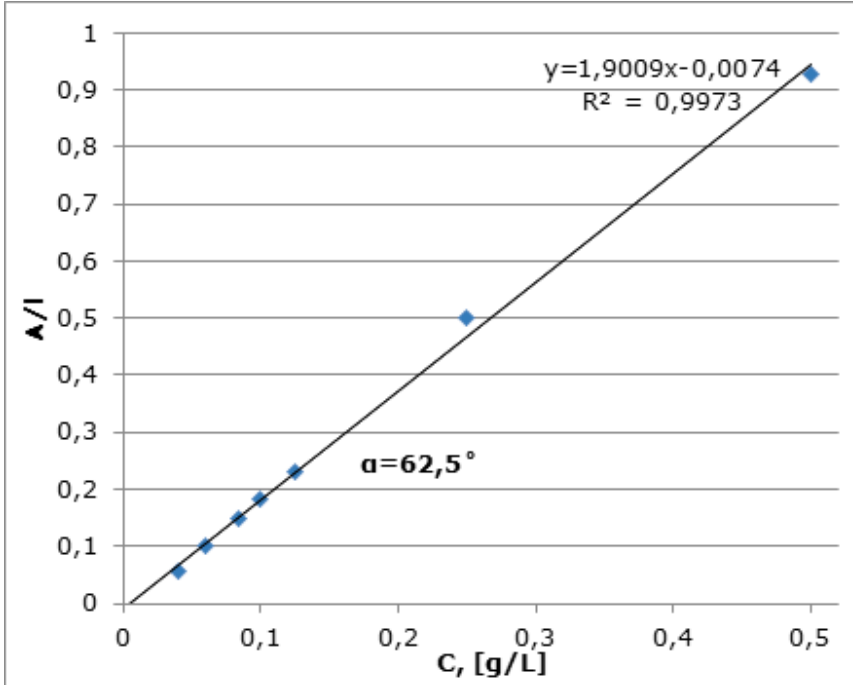

Figure 2: Graph of $\mathrm{A} / \mathrm{I}$ and $\mathrm{C}$ dependence of "HF" solution. obtained by thermal method. 
Based on the results obtained by the spectrophotometric method, it was determined that the molecular mass of "HF" obtained by the thermal method using formula (Eq. 2) is 246.6 $\mathrm{kDa}$. The molecular mass of "HF" obtained from silk fibroin under the influence of UHF rays in an acidic medium was also determined by spectrophotometry. The light absorption of "HF" solutions obtained under the influence of UHF rays was determined and the $\mathrm{A} / \mathrm{I}-\mathrm{C}$ correlation graph was plotted (Figure 4).

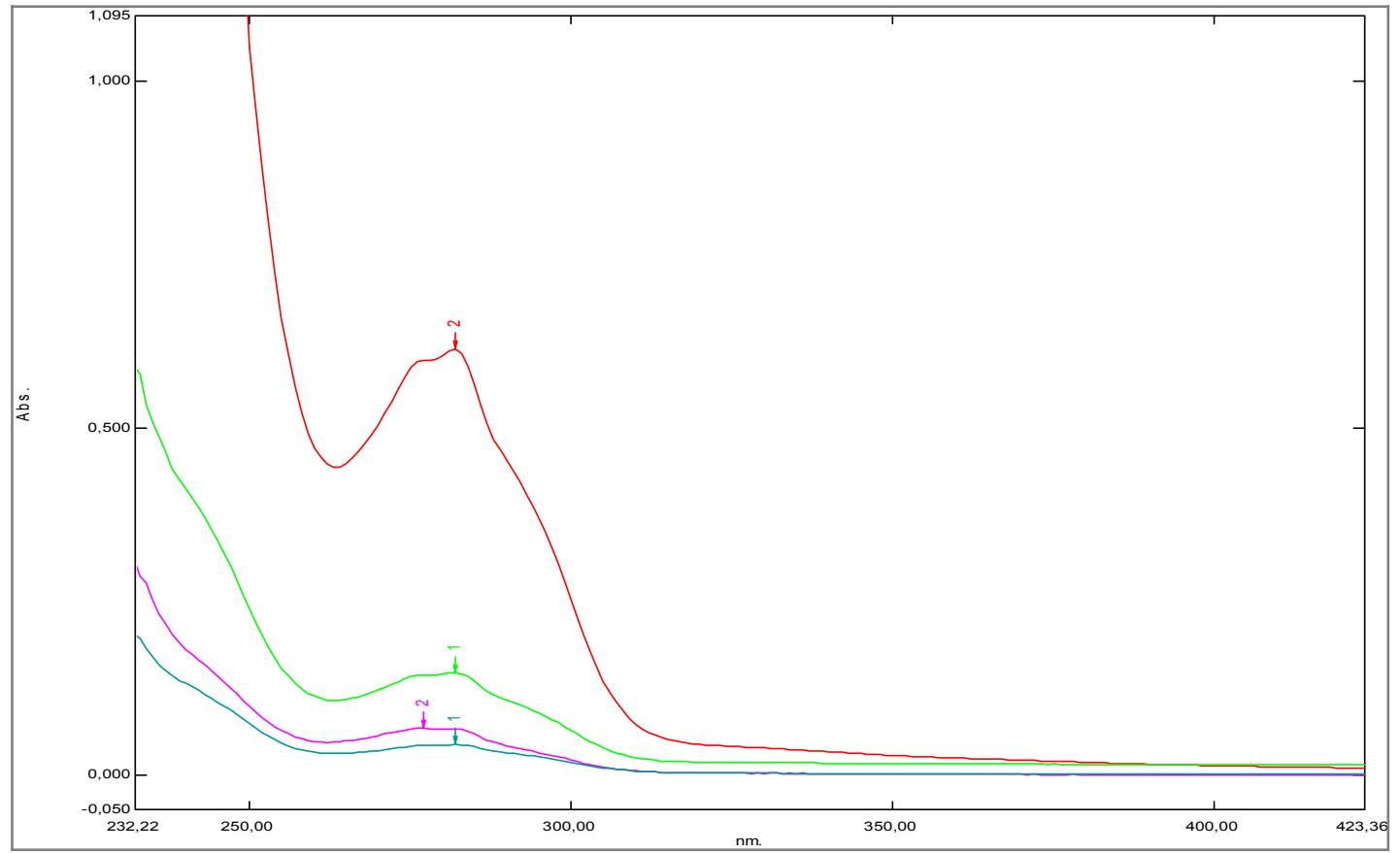

Figure 3: UV spectra of "HF" solutions obtained under the influence of UHF rays.

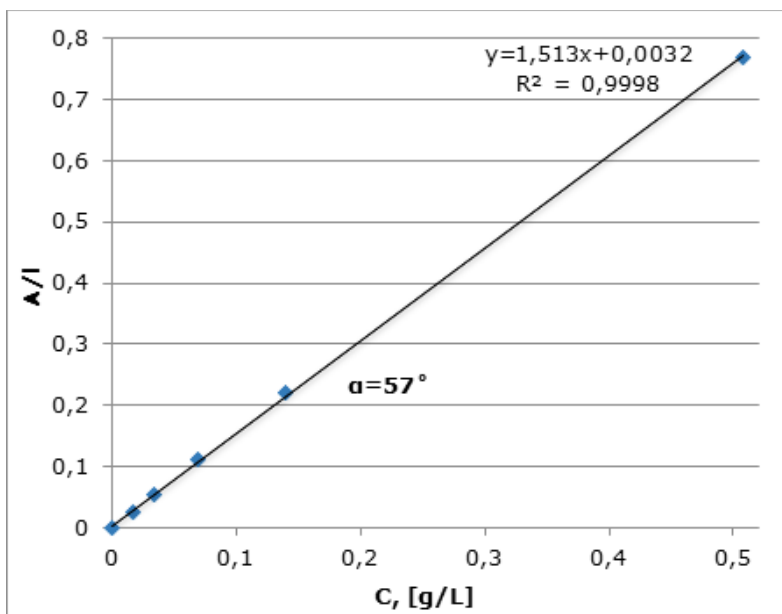

Figure 4: Graph of $\mathrm{A} / \mathrm{I}$ and $\mathrm{C}$ dependence of "HF" solution obtained under the influence of UHF rays.

The angular length of the graph line relative to the concentration (C) axis was found to be $57^{\circ}$. The molecular mass of "HF" obtained under the influence of UHF rays was found to be $307 \mathrm{kDa}$ using formula (Eq. 2).

\section{CONCLUSION}

We hypothesized that the reason for the differences between the molecular masses of "HF"s obtained by thermal methods and under the influence of UHF rays is that the process of obtaining "HF" takes place at different times. Because it takes more time to obtain "HF" from silk fibroin by thermal methods, fibroin molecules are hydrolyzed into smaller pieces. Therefore, it can be observed that the masses of "HF" molecules obtained by thermal methods are smaller. 
Determining the molecular mass of fibroincontaining proteins using the method of spectrophotometry is superior to other methods of determining the molecular mass with speed and low cost, accuracy. In this method, the determination of molecular mass is almost unaffected by various external factors. In determining the molecular mass, coagulation, and sedimentation of the protein in solution may adversely affect the results. Therefore, special attention should be paid to the state of the solution of the protein, the molecular weight of which is determined.

\section{REFERENCES}

1. Wang $Y J$, Zhag $Y Q$. Three-Layered Sericins around the Silk Fibroin Fiber from Bombyx mori Cocoon and their Amino Acid Composition. AMR. 2011 Jan;175-176:158-63. <DOI>.

2. Liu $X$, Zhang K-Q. Silk Fiber - Molecular Formation Mechanism, Structure- Property Relationship and Advanced Applications. In: Lesieur C, editor. Oligomerization of Chemical and Biological Compounds [Internet]. InTech; 2014 [cited 2021 Dec 11]. ISBN: 978-953-51-1617-2. $\leq \mathrm{URL}>$

3. Sashina E, Heinemann K, Horst B, Novoselov N, Frank M. Method for dissolving natural silk. Russian Federation Patent, no: 2385649, 2007.

4. Kunz RI, Brancalhão RMC, Ribeiro L de FC, Natali MRM. Silkworm Sericin: Properties and Biomedical Applications. BioMed Research International. 2016;2016:1-19. <DOI>.

5. Brestkin YuV. Dynamic coil-extended chain phase transition in the longitudinal field. Acta Polym. 1987 Aug;38(8):470-7. <DOI>.

6. Geller B, Geller A, Chirtulov V. Practical Guide to
Physical Chemistry of Fiber-Forming Polymers. Vol. 432. 1996. 432 p.

7. David V. Introduction to Biophysics. Mir Publishers; 1982. $210 \mathrm{p}$.

8. Zhang H, Li L, Dai F, Zhang H, Ni B, Zhou W, et al. Preparation and characterization of silk fibroin as a biomaterial with potential for drug delivery. J Transl Med. 2012 Dec;10(1):117. <DOI>.

9. Tanaka K, Inoue S, Mizuno S. Hydrophobic interaction of P25, containing Asn-linked oligosaccharide chains, with the $\mathrm{H}-\mathrm{L}$ complex of silk fibroin produced by Bombyx mori. Insect Biochemistry and Molecular Biology. 1999 Mar;29(3):269-76. <DOI $>\mathrm{H}$.

10. Holmes F, Smith D. Sedimentation and Diffusion of Soluble Fibroin. Nature. 169:193. $\leq \mathrm{URL}>$.

11. Coleman D, Howitt F. Studies on silk proteins I. The properties and constitution of fibroin. The conversion of fibroin into a water-soluble form and its bearing on the phenomenon of denaturation. Proc R Soc Lond A. 1947 Jul 8;190(1021):145-69. $\leq \mathrm{DOI}>$.

12. Feng $Y$, Lin J, Niu L, Wang $Y$, Cheng $Z$, Sun $X$, et al. High Molecular Weight Silk Fibroin Prepared by Papain Degumming. Polymers. 2020 Sep 16;12(9):2105. <DOI $>$.

13. Eshchanov KO, Baltayeva M, Sarimsakov A. Determination of the Molecular Mass of Silk Fibroin Using the Method of Spectrophotometry. Annals of RSCB. $2021 ; 25(2): 4083-90$. $\leq$ URL $>$.

14. Eshchanov KO, Baltayeva M, Sarimsakov A. Purification of Cottonseed Oil Using A Sorbent Obtained from the Fibrous Waste of Natural Silk. Annals of RSCB. $2021 ; 25(1): 692-8$. $\leq$ URL $>$. 
